\title{
O PNAIC e a produção de textos escritos: uma reflexão acerca do material formador
}

\author{
PNAIC and the production of written texts: a reflection about former material \\ Lainy Martinelli dos Santos \\ Zaira Bomfante dos Santos
}

Resumo: O presente trabalho ${ }^{1}$ consiste em uma reflexão a respeito dos cadernos de formação do Pacto Nacional pela Alfabetização na Idade Certa (PNAIC), programa de formação continuada de professores alfabetizadores. O objetivo do estudo consiste na compreensão do modo com que os cadernos trazem o ensino e a aprendizagem da Língua escrita, dando ênfase para a produção de texto, seu conceito e aplicação no processo de Alfabetização. Ancoramos nossa visão de Linguagem na perspectiva sociointeracional, a partir das contribuições de Bakhtin (1992), compreendendo-a como um espaço dialógico, potenciador de interações sociais e desenvolvimento humano. Adotamos, para o estudo, a pesquisa bibliográfica como metodologia, observando as teorias e atividades presentes nos materiais didáticos disponibilizados pelo Pacto. Entendemos que o PNAIC nasce como uma política educacional para melhoria da educação no campo da Alfabetização. Portanto, compreender os conceitos e teorizações presentes nos cadernos acerca da Língua escrita nos indica o tipo de educação que se pretende desenvolver nas salas de aula. Podemos afirmar, portanto, que as ações realizadas pelo PNAIC constituíram intervenção necessária para melhoria do processo de Alfabetização. No entanto, devemos nos alertar para o fato de que os problemas na Alfabetização não serão sanados somente pelo professor. É necessário desviar o olhar para além dos profissionais, creditando mudança a todos os contextos escolares, desde a formação docente às estruturas físicas.

Palavras-chave: PNAIC. Alfabetização. Formação continuada.

Abstract: The present work consists of a reflection on the formation books of the National Pact for Literacy at the Right Age (PNAIC), a program of continuing education for literacy teachers. The aim of the study is to understand the way notebooks bring the teaching and learning of written language, emphasizing the production of text, its concept and application in the Literacy process. We anchor our view of Language in the sociointeractional perspective, based on the contributions of Bakhtin (1992), understanding it as a dialogical space, enhancer of social interactions and human development. For the study, we adopted bibliographical research as a methodology, observing the theories and activities present in the teaching materials made available by the Pact. We understand that PNAIC is born as an educational policy to improve education in the field of literacy, therefore, understanding the concepts and theorizations present in the notebooks about written language indicates the type of education that is intended to develop in classrooms. Therefore, we can say that the actions carried out by PNAIC constituted a necessary intervention to improve the literacy process. However, we should be aware that literacy problems will not be solved only by the teacher. It is necessary to look away from the professionals, crediting change to all school contexts, from teacher training to physical structures.

Keywords: PNAIC. Literacy. Continuing education.

\footnotetext{
1 Este trabalho é parte de uma pesquisa realizada para a dissertação de mestrado da autora, entre os anos de 2018 e 2019.
} 


\section{Introdução}

Neste trabalho objetivamos refletir sobre os materiais do Pacto Nacional pela Alfabetização na Idade Certa (PNAIC), que consiste em um programa de formação continuada de professores alfabetizadores. O interesse de estudo surgiu dos questionamentos acerca do modo com que o ensino da Língua escrita permeia a bibliografia do programa, dando ênfase para a produção de texto, seu conceito e aplicação no processo de Alfabetização.

Analisar a bibliografia do programa se fez ${ }^{2}$ necessária, visto que esse, de abrangência nacional, implicou reflexões e mudanças não só conceituais, mas práticas, nas relações de ensino e aprendizagem efetivadas nas turmas do Ensino Fundamental. O estudo do PNAIC nos ajudará a compreender a concepção de Alfabetização que permeou os documentos, assim como perceber o papel da produção textual neste processo. Para tanto, vale ressaltar que não assumiremos uma postura crítica a respeito da construção e desdobramentos do Pacto na sociedade educacional. Nosso objetivo, neste momento, se restringe a observação de como o ensino da Língua escrita permeia os documentos, assumindo uma postura analítica, a fim de compreender os reflexos destas concepções na relação de ensino e aprendizagem em sala de aula.

Objetivando compreender as concepções e orientações trazidas pelo Pacto, analisaremos, no primeiro momento, o histórico de criação e implementação do programa no Brasil, evidenciando a natureza desse. Posteriormente, ancorados em uma metodologia de pesquisa bibliográfica, analisaremos as teorizações contidas no material do PNAIC, discutindo sobre as concepções contidas ali e refletindo a respeito das orientações sobre o processo de ensino e aprendizagem da Língua escrita na Alfabetização.

A formação continuada de professores não é tema recente. Diversas razões têm movido à criação de políticas públicas visando à formação docente. Dentre elas, se destaca o baixo índice de desempenho dos alunos do Ensino Fundamental frente às avaliações de larga escala. Diante disto, nasce a crença

\footnotetext{
${ }^{2}$ As análises aqui tecidas foram realizadas no ano de 2018. Os relatos serão realizados no tempo passado, pois o PNAIC teve seu fim no estado do Espírito Santo, sendo substituído por outro programa de Formação Continuada, o Pacto pela Aprendizagem no Espírito Santo (PAES).
} 
de que a formação docente seria meio satisfatório para recuperação ou amenização dos desempenhos escolares. Segundo o próprio documento oficial, Referenciais para Formação de Professores,

Não se trata de responsabilizar pessoalmente os professores pela insuficiência das aprendizagens dos alunos, mas de considerar que muitas evidências vêm revelando que a formação de que dispõem não tem sido suficiente para garantir o desenvolvimento das capacidades imprescindíveis para que crianças e jovens não só conquistem sucesso escolar, mas, principalmente, capacidade pessoal que lhes permita plena participação social num mundo cada vez mais exigente sob todos os aspectos (BRASIL, 1999, p. 26).

Este mesmo documento conceitua que, portanto

A formação continuada deve propiciar atualizações, aprofundamento das temáticas educacionais e apoiar-se numa reflexão sobre a prática educativa, promovendo um processo constante de auto-avaliação que oriente a construção contínua de competências profissionais (BRASIL, 1999, p. 70).

A formação continuada tem se tornado exigência na sociedade atual, tendo como referência não só políticas públicas de formação ao nível macro, mas reflexões integradas no cotidiano escolar. Conhecer estas políticas e ações se torna imprescindível para compreender a concepção de escola, professor e sujeito que visamos formar.

\section{O PNAIC como política pública em educação: do histórico aos desdobramentos}

É importante salientar neste momento quais concepções nos guiam ao falar sobre políticas públicas para a educação. Souza (2003) conceitua que,

[...] o processo de formulação de política pública é aquele através do qual os governos traduzem seus propósitos em programas e ações, que produzirão resultados ou as mudanças desejadas no mundo real (SOUZA, 2003, p. 13).

Portanto, ao traçar as políticas públicas, um governo demonstra quais ações julga necessárias realizar dentro de um campo específico. Por exemplo, ao produzir o PNAIC, o governo demonstra sua preocupação com a Alfabetização no Brasil, criando ações que visam mudanças desejadas. 
A criação de políticas públicas voltadas para a formação continuada de professores tem sido recorrente no cenário educacional. O motivo quase sempre esteve atrelado aos resultados das avaliações de larga escala. Dados disponibilizados sobre as capacidades de leitura e escrita pelo SAEB (sistema de avaliação da educação básica), Prova Brasil, e até mesmo a ANA (avaliação nacional da alfabetização), criada após a implantação do PNAIC, nos faz refletir sobre o contínuo esforço de melhoria.

Os resultados do SAEB têm variação de 0 a 500 pontos. A medida que os alunos vão acumulando habilidades ${ }^{3}$, mais alto na escala da pontuação ficarão. O que preocupa nos resultados é que a média do Brasil não alcançava nível intermediário de satisfação. No ano de 2005, por exemplo, a média brasileira era de 175 pontos. 2011, ano posterior a criação do PNAIC, a média era de 191 pontos. O mesmo ocorria com a Prova Brasil, exame realizado com o $5^{\circ}$ e $9^{\circ}$ ano do Ensino Fundamental. Em 2011, na categoria de Língua Portuguesa, a maior incidência dos alunos do $5^{\circ}$ ano se encontrava no nível 3 de proficiência $(19,46 \%)$, tendo ainda $6,99 \%$ de crianças que se encontravam no nível 0 . Foram a partir desses dados que presenciamos uma crescente criação de formações continuadas no país.

O PNAIC, foco deste trabalho, não foi à primeira política visando o processo de Alfabetização, e tampouco será a última. Parafraseando Soares (2014), temos vivenciado o futuro de programas de Alfabetização, e toda política presente defende ser a mais acertada. É visando conhecer esta trajetória, até a implantação do PNAIC, que abaixo explicitamos alguns programas de formação anteriores a ele.

De início, temos no ano de 2001, a fundação do PROFA - Programa de Formação de Professores Alfabetizadores, cujo objetivo era desenvolver competências didáticas aos professores que ensinavam a leitura e a escrita nas escolas de Ensino Fundamental. Teve como base o conceito de que a escola deve valorizar os conhecimentos e saberes advindo do alunado e das experiências dos professores.

\footnotetext{
${ }^{3}$ Dados disponíveis do portal INEP: <portal.inep.gov.br> acesso em: 06 de dezembro de 2018
} 
A metodologia de formação proposta neste curso considera, entre outros aspectos, que o ponto de partida para dar início ao processo de reflexão sobre a prática pedagógica de alfabetização é levar em conta o que os professores sabem e pensam a respeito, potencializar os saberes individuais e discutir os pressupostos que os determinam. Essa dinâmica de trabalho supõe a problematização, a busca coletiva de soluções, a teoria como fonte de informação para interpretar e reconstruir a prática pedagógica (BRASIL, 2001, p.4).

A partir de 2005, o governo federal lança o Pró-Letramento, cujo principal objetivo era fornecer aos professores alfabetizadores suporte para uma melhor qualidade do ensino da leitura, escrita e da matemática nas séries iniciais do ensino fundamental. Neste programa de formação, já dando indícios do que posteriormente se intensificaria no $\mathrm{PNAIC}^{4}$, adota-se uma postura que tem a concepção do Letramento como guia, aproximando o ensino da leitura e escrita ao meio social do aluno. Também considera a Linguagem como pivô da interação verbal, valorizando os diversos usos da Língua nos diferentes contextos sociais (BRASIL, 2007).

E foi no ano de 2009, que a emenda constitucional $n^{\circ} 59 / 2009$ tornou o Plano Nacional de Educação (PNE) uma exigência constitucional, de periodicidade decenal. Na meta 5 do plano, institui-se que todas as crianças devem ser alfabetizadas até o final do $3^{\circ}$ ano do Ensino Fundamental, assim como atingir nota 6,0 (Anos iniciais do Ensino Fundamental) no Índice de Desenvolvimento da Educação Básica- IDEB (meta 7).

Dentro deste contexto, em 2012 é instituído o Pacto Nacional pela Alfabetização na ldade Certa (PNAIC), como forma de melhoria da educação frente aos desempenhos avaliativos e visando cumprir as metas estabelecidas pelo PNE.

\footnotetext{
${ }^{4}$ Afirmamos isto, pois, majoritariamente, as concepções teóricas que guiaram o pró-letramento estão presentes nos cadernos do PNAIC. Foi com o pró-letramento que os estudos do Letramento começaram a se efetivar concretamente nas escolas, momento onde muitos professores a conheceram, assim como os teóricos que dialogavam sobre. O PNAIC retoma estes conceitos, acrescentando novos estudos e referenciais para o diálogo, fornecendo também momentos práticos para a transposição das leituras para o fazer docente.
} 
O Pacto, ocorrido do ano de 2012 a $2018^{5}$, foi uma parceria firmada entre o governo federal, os estados e municípios através da portaria ${ }^{\circ} 867$, em 4 de julho de 2012. As ações do Pacto foram objetivadas da seguinte forma:

I- Garantir que todos os estudantes dos sistemas públicos de ensino estejam alfabetizados, em Língua Portuguesa e em Matemática, até o final do $3^{\circ}$ ano do ensino fundamental;

II- reduzir a distorção idade-série na Educação Básica;

III- melhorar o Índice de Desenvolvimento da Educação Básica IDEB; e

IV- contribuir para o aperfeiçoamento do desempenho dos professores (BRASIL, 2017b, p. 2).

A formação do PNAIC esteve totalmente focada nas práticas docentes, de modo que o trabalho pedagógico virasse objeto de reflexão. "Refletir, estruturar e melhorar a ação docente é, portanto, o principal objetivo da formação" (BRASIL, 2012, p.28).

A estrutura da formação continuada se deu em um tripé de profissionais. No primeiro grupo, os professores formadores, profissional selecionado pelas universidades públicas parceiras do PNAIC, que realizavam a formação dos orientadores de estudo. Estes, por sua vez, escolhidos pelos municípios participantes, são os profissionais que ministraram as formações dos professores alfabetizadores. Este último grupo de profissionais foram os responsáveis por fazer a diferença no âmbito escolar, estando em contato direto com os alunos das séries iniciais do Ensino Fundamental (BRASIL, 2015).

Desde sua criação, o material ${ }^{6}$ formador base disponibilizado pelo PNAIC contava com uma coleção de 12 arquivos $^{7}$ : o caderno para gestores, o caderno

\footnotetext{
${ }^{5}$ No Espírito Santo, no ano de 2018, o PNAIC foi substituído pelo Pacto pela Aprendizagem no Espírito Santo (PAES).

${ }^{6}$ Materiais relativos ao PNAIC estão disponíveis no site do PNAIC (http://pacto.mec.gov.br/). Na página inicial, o site apresenta as informações sobre o porquê de o Pacto ter sido firmado, quais são os princípios a serem considerados ao longo do desenvolvimento das atividades e quais os compromissos assumidos pelos entes governamentais ao aderirem a ele, além da carga horária que será dedicada às formações de professores e das formas de avaliação que serão empregadas para verificar o funcionamento do Pacto.

${ }^{7}$ Para esse estudo, visando conhecer as teorias e reflexões ofertadas, analisamos os cadernos de Volume V e VII, disponibilizados no ano de 2015 e 2017.
} 
de apresentação e 10 cadernos focados nos conteúdos teóricos da formação. Analisando o material nos deparamos com alguns eixos em comum, foram eles:

- O trabalho com a interdisciplinaridade;

- Adequação do currículo para promoção da igualdade de direitos, individualidade dos alunos e a inclusão;

- A utilização de diferentes recursos didáticos;

- A aplicação do conceito de letramento nas práticas docentes.

Os estudos ofertados pelo PNAIC procuraram articular as temáticas do cotidiano escolar, tais como currículo, planejamento, avaliação, associando as teorizações trazidas nos cadernos, de modo a enriquecer as práticas docentes realizadas nas salas de Alfabetização.

É a partir daqui que nasce nosso interesse de estudo: a tentativa de compreensão destas teorizações trazidas pelo documento, refletindo em como este material potencializa a formação dos professores alfabetizadores e sua prática docente.

\section{A concepção de Alfabetização e Letramento presentes no PNAIC}

Ao adotar um conceito de Alfabetização, o PNAIC esperava uma postura diferenciada do professor, que complementasse ou transformasse sua prática. A internalização desta concepção o guiaria no processo educativo, ajudando a formular caminhos, produzir atividades, tecer avaliações. Portanto, ao adotar um conceito teórico, este reflete constantemente nos modos como o professor guia sua docência.

Por essa razão é de suma importância compreender os conceitos traçados pelo PNAIC, visto que estes refletiram e continuam a perpassar as salas de aula, a dinâmica docente, o ensino e aprendizagem da Língua Escrita. Abaixo, evidenciamos alguns dos conceitos-chave adotado pelo Pacto.

A concepção de Alfabetização presente nos cadernos do PNAIC é na perspectiva do Letramento. Aqui, entende-se que é preciso que a criança domine o sistema linguístico, porém que ela também consiga, com autonomia, fazer uso da Língua nas diversas situações comunicativas do cotidiano.

Magda Soares é uma das autoras referência para entender a concepção da Alfabetização na perspectiva do letramento; é autora em que o PNAIC majoritariamente se apoia. Segundo Soares (2010) "alfabetizar e letrar são duas 
ações distintas, mas não inseparáveis, ao contrário: o ideal seria alfabetizar letrando, ou seja: ensinar a ler e escrever no contexto das práticas sociais da leitura e da escrita [...]" (p.47).

Porém, é necessário compreender que

[...] alfabetização - entendida como a aquisição do sistema convencional de escrita- distingue-se do letramento- entendido como o desenvolvimento de comportamentos e habilidades de uso competente da leitura e da escrita em práticas sociais: distinguem-se tanto em relação aos objetos de conhecimento quanto em relação aos processos cognitivos e linguísticos de aprendizagem e, portanto, também de ensino desses diferentes objetos (SOARES, 2004, p. 97).

Portanto, sendo letramento e alfabetização ações indissociáveis, a criança alfabetiza-se, constrói seu conhecimento do sistema alfabético e ortográfico, em situações de letramento, ou seja, no contexto social, na interação com materiais escritos reais, e não artificialmente construídos. E, por outro lado, a possibilidade de participação nos contextos reais comunicativos só será possível por meio, e em dependência, do processo de aprendizagem dos códigos linguísticos (SOARES, 2004). A autora ainda afirma que

Esse alfabetizar letrando, ou letrar alfabetizando, pela integração e pela articulação das várias facetas do processo de aprendizagem inicial da língua escrita, é, sem dúvida, o caminho para a superação dos problemas que vimos enfrentando nesta etapa da escolarização (SOARES, 2004, p. 100).

Nessa direção, Rojo situa que o termo Letramento

Busca recobrir os usos e práticas sociais de linguagem que envolvem a escrita de uma ou de outra maneira, sejam eles valorizados ou não valorizados socialmente, locais (próprios de uma comunidade específica) ou globais, recobrindo contextos sociais diversos (família, igreja, trabalho, mídias, escola, etc.), em grupos sociais e comunidades diversificadas culturalmente (ROJO, 2010, p. 26).

Ou seja, o conceito de letramento vai para além do âmbito escolar. 0 docente, ao alfabetizar letrando, vai além do codificar e decodificar. Vai, no sentido literal, preparar o aluno para a sociedade em que vive, interagindo nas relações sociais que está inserido. Afinal, 
Estar Alfabetizado significa ser capaz de interagir por meio de textos escritos em diferentes situações; significa ler e produzir textos para atender a diferentes propósitos. A criança alfabetizada compreende o sistema alfabético de escrita, sendo capaz de ler e escrever, com autonomia, textos de circulação social que tratem de temáticas familiares a ela; como é capaz de compreender igualmente princípios básicos de outras linguagens como a matemática, as artes e outras ciências (SILVEIRA et al., 2016, p.12).

A escola se torna, portanto, a instituição responsável pelo ensino da língua escrita, de seu funcionamento, suas convenções, tendo objetivo final à ampliação das competências comunicativas, visando maiores participações sociais (BRASIL, 2015). Embora o letramento não esteja, em sua totalidade, vinculado a escola, é ali que este se intensifica, associado à Alfabetização, ao ensino sistemático da língua escrita. Afinal, o mero convívio com os textos escritos na sociedade não garante que os alunos se apropriem da escrita alfabética, pois a aprendizagem desta não é espontânea e demanda reflexão sobre o sistema de escrita (ALBUQUERQUE, 2007).

É neste sentido que, o Pacto prevê que o professor, "em sua sala de aula, possibilite as crianças mais do que apenas ler e escrever algumas palavras soltas e descontextualizadas ou textos forjados sem sentido" (BRASIL, 2015, p. 25). Espera que o professor consiga, em sua prática, alfabetizar letrando.

Através da formação continuada, o PNAIC almejava significativas mudanças no fazer docente dos profissionais que atuam nas séries iniciais do Ensino Fundamental. Nos encontros do Pacto, os professores tiveram a oportunidade de compartilhar os anseios e dificuldades advindas da sala de aula, assim como as experiências positivas, refletindo e ressignificando sua prática por meio de concepções e experiências outras apreendidas.

\section{O Professor Alfabetizador}

A palavra-chave da formação do PNAIC era reflexividade. O termo coloca o professor como aquele que desempenha o papel ativo na formulação de objetivos e conclusão de seu trabalho. A reflexão, para Zeichner (2003) significa que a geração de conhecimento sobre ensino e aprendizagem não é propriedade exclusiva de faculdades, universidades e centros de pesquisa e 
desenvolvimento, um reconhecimento que os professores também têm teorias que podem contribuir para a construção de conhecimentos comuns sobre boas práticas de ensino, rompendo, assim, com a tendência tecnicista, que meramente cumprem, na condição passiva, o que foi colocado/prescrito por outros.

O professor se tornou o eixo central, o protagonista da formação. Sua prática docente foi seu objeto e seu lócus de estudo. A reflexividade docente surge "no intuito de buscar compreender e transformar a realidade (escolar) complexa, desafiadora e multifacetada que se apresenta atualmente" (BRASIL, 2015 , p. 53). A reflexividade torna-se mecanismo eficiente, pois, "cotidianamente, os professores partilham seus saberes uns com os outro através do material didático, dos macetes, dos modos de fazer, dos modos de organizar a sala de aula" (TARDIF, 2001, p.53). Ou seja, foi como se o Pacto institucionalizasse algo que já ocorria, em nível micro, agora ao nível nacional, compartilhando suas experiências (positivas e negativas), aprendendo com elas e também com as alheias.

Foi nesta razão que os documentos orientadores do Pacto instituíram como princípio norteador a seguinte diretriz de formação:

III- O respeito ao protagonismo do professor e a um espaço-tempo que Ihe permita refletir criticamente e aperfeiçoar sua prática;

IV- O diálogo e a parceria com atores e instituições competentes, capazes de contribuir para alavancar novos patamares de qualidade ao complexo trabalho de gestão da sala de aula e da instituição educativa (BRASIL, 2017a, p.15).

Ou seja, espera-se que o professor seja reflexivo sobre sua prática, conte com o auxílio dos materiais para aprendizagem e transponha todas estas contribuições para sua prática docente. Libâneo (2004) já nos adiantava como realizar esta ação. Para o autor o

[...] trabalho de professor implica compreender criticamente o funcionamento da realidade e associar essa compreensão com seu papel de educador, de modo a aplicar sua visão crítica ao trabalho concreto nos contextos específicos em que ele acontece (LIBÂNEO, 2004, p. 40). 
Também, ao trazer o ato reflexivo, os cadernos do PNAIC destacam a necessidade do professor conhecer seus alunos, suas dificuldades $\mathrm{e}$ potencialidades. É buscar entender o ritmo de aprendizagem de cada um, assim como desenvolver diferentes práticas pedagógicas que deem a possibilidade da inclusão de todos.

As diferenças de aprendizagem e os ritmos dos alunos são algumas características e situações presentes nas salas de aula que emergem no cotidiano escolar e exigem que o professor mobilize seus conhecimentos para poder compreendê-los e, assim, tome decisões que atendam a essas necessidades. Esse movimento de analisar, refletir e tomar decisões exige e desafia o professor a repensar a sua prática pedagógica (BRASIL, 2015, p. 54).

Conhecer seu cotidiano escolar é ato obrigatório para um professor reflexivo. Adotar posturas que torne o professor um pesquisador da própria prática pedagógica sempre foi objetivo da formação do PNAIC, sendo indispensável se tornar um profissional indagador e que assume a realidade como objeto de pesquisa e de reflexão. Assim, a pesquisa não fica restrita somente aos professores da academia ou aos que estão matriculados em cursos de mestrado ou doutorado (BRASIL, 2015).

\section{O aluno em contexto de alfabetização}

Quando há a formação reflexiva, a prática pedagógica passa a ser atenta ao educando. O conhecimento trazido por tal e a aquisição dos novos se integram na construção da vida educativa do aluno. Portanto, este passa a ser sujeito ativo na construção do conhecimento, sujeito que tem voz e precisa ser ouvido.

Os cadernos do PNAIC apresentam a criança como detentora de direitos: direito a educação, a estar alfabetizada até os 8 (oito) anos de idade, a ter seu ritmo de aprendizagem, de aprender de forma lúdica e contextualizada, o direito de ter infância (BRASIL, 2015b).

$\mathrm{Na}$ formação, os professores foram levados a compreender os conceitos de "infância" e "criança" em sua pluralidade, sendo eles produtos de uma construção sociocultural (BRASIL, 2015b). Portanto, são crianças que desde 
cedo encontram-se inseridas em contextos letrados, onde a linguagem é principal objeto de comunicação. Com esse entendimento a Alfabetização das crianças é vista no PNAIC como processo que deve ir além da compreensão do sistema de escrita alfabética, criando capacidades de leitura e escritura de textos em diferentes gêneros, para interagirem nesse ambiente social em que vivem.

\section{A produção textual nos cadernos formadores do PNAIC}

Não há como negar que as crianças, ao adentrar à escola, possuem uma gama de vivências com a Linguagem, gêneros escritos, textos com distintas linguagens, sua produção e interpretação. Isto, pois, em uma sociedade letrada como a nossa, a linguagem circula em abundância no cotidiano social (BRASIL, 2015c).

Diante deste cenário, o PNAIC traz a escola como instituição responsável pelo ensino sistemático da Língua escrita, e o ensino da utilização desta pelos alunos nas práticas letradas do cotidiano. Portanto, a escola é dada como o espaço de desenvolvimento e ampliação da escrita (e da leitura), nos mais variados gêneros, ligados ao cotidiano do aluno (BRASIL, 2015c).

A concepção de Linguagem que permeia o exercício da produção textual nos cadernos do PNAIC é a da interação verbal. Seja por meios orais ou escritos, a Linguagem tem o objetivo de comunicar, prevê o diálogo social entre parceiros no cotidiano. Ou seja, no sentido Bakhtiniano (1992), a verdadeira essência da língua é constituída pelo fenômeno social da interação verbal. A linguagem, retratada no PNAIC, é fruto da interação entre sujeitos, na dialogia do cotidiano.

Portanto, no ensino da produção textual, é imprescindível a compreensão de que não há produção sem o outro, sem interação. Na verdade, é pelo outro, nesse processo de interação, que o texto é formulado. Ou seja,

[...] a palavra dirige-se a um interlocutor: ela é função da pessoa desse interlocutor: Variará se se tratar de uma pessoa do mesmo grupo social, se estiver ligada ao interlocutor por laços sociais mais ou menos estreitos (pai, mãe, marido, etc.). Não pode haver interlocutor abstrato; não teríamos linguagem comum com tal interlocutor, nem no sentido próprio (BAKHTIN, 1981, p. 112). 
É exatamente por esse processo de interação, que o professor precisa se colocar como leitor dos textos produzidos pelos alunos, não somente para corrigi-los, mas para fazer papel de interlocutor, concordando, discordando, se posicionando sobre o dizer do aluno, dando-lhe indícios e caminhos para a real apreensão da linguagem escrita (BRASIL, 2015c).

Essa interação entre os sujeitos é que produz o caráter dialógico da Linguagem para Bakhtin.

[...] o ouvinte, ao perceber e compreender o significado (linguístico) do discurso ocupa simultaneamente em relação a ele uma ativa posição responsiva: concorda ou discorda dele (total ou parcialmente), completa-o, aplica-o, prepara-se para usá-lo, etc.; essa posição responsiva do ouvinte se forma ao longo de todo o processo de audição e compreensão desde o seu início, às vezes literalmente a partir da primeira palavra do falante (BAKHTIN, 1997, p. 271).

Pensar a linguagem com interação no processo de ensino, sua dialogicidade, significa dar vez e voz as crianças, trazer para a sala de aula suas vivências, possibilitara ampliação de seus repertórios, o que elas já trazem de casa, de seus bairros... de suas vidas (SILVEIRA et al. 2016).

Além da compreensão de que a escrita se dá para o outro, possibilitar a voz da criança também Ihe garante maior repertório de fala. Antunes (2003) já nos alerta:

Ter o que dizer é, portanto, uma condição prévia para o êxito da atividade de escrever. Não há conhecimento linguístico (lexical ou gramatical) que supra a deficiência do "não ter o que dizer". [...] se faltam as ideias, se falta a informação, vão faltar as palavras. Daí que nossa providencia maior deve ser encher a cabeça de ideias, ampliar nosso repertório de informações e sensações, alargar nossos horizontes de percepção das coisas (p. 47, grifo do autor).

Portanto, não há texto sem discurso. Não há sentido sem ideias. Não existe sujeito fora de seu contexto. Assim como não há produção textual que não seja perpassada por dizeres vividos no social.

Evidenciando as análises dos cadernos, o PNAIC afirma que não é qualquer escrita realizada na escola que mostra a realidade da linguagem, a língua viva, relevante, social e comunicativa. Os cadernos trazem os estudos de Schneuwly (1985) sobre o desenvolvimento da produção de textos escritos. 
Segundo o autor, o desenvolvimento da Linguagem escrita exige operações mentais que perpassam três níveis ou instâncias. São nestas etapas que o planejamento docente de uma produção textual deveria se firmar:

1. Criação de uma base de orientação: Diz respeito às condições de produção. Portanto, o lugar social do autor, seus interlocutores, sua finalidade, conteúdo do discurso, orientação do processo de escrita (o que tenho para dizer? para quem vou falar/escrever? com que objetivo? em que circunstâncias? em que condições meu texto será ouvido/lido?);

2. Gestão textual: Momento de tomada de decisões a respeito da ancoragem enunciativa e do planejamento do texto, onde o autor se questiona o "como dizer?". Organização dos conteúdos (o que tem a dizer), e qual modelo de texto é adequado para a situação (gêneros textuais).

3. Linearização: Conjunto de operações que transformarão o que foi pensado, em texto escrito. Se expressar por meio das letras, palavras, sentenças, parágrafos, ou seja, enunciados, tudo o que foi planejado, tendo sempre em mente o objetivo da escrita, o interlocutor e as condições nas quais ele será lido.

Mesmo havendo estes pontos a serem analisados ao planejar uma produção textual, o autor afirma que nada é estanque ou linear no processo de criação. O importante é que a criança tenha noção de "o que escrever? Para que? Para quem? Como posso dizer?". Portanto, o PNAIC reforça a ideia de que na escola devem ser desenvolvidas oportunidades em que os alunos escrevam

[...] para diferentes interlocutores (adultos, crianças, pessoas próximas ou distantes) e não apenas para ele, professor; escrever com diferentes finalidades (contar algo, registrar um episódio, reclamar, elogiar, argumentar, noticiar etc.), lidando, portanto, com diferentes contextos e tipos de conteúdo discursivo (BRASIL, 2015c, p.51).

O papel do educador, portanto, é o ensino da língua viva, na interação, nas atividades socioculturais (BRASIL, 2015c). A criança deve aprender a escrever, escrevendo de verdade, se tornando autora, se posicionando sobre o lugar que vive, tendo interlocutores, desenvolvendo diversos gêneros textuais, para desde o princípio, entender o lugar da escrita no cotidiano real. 


\section{Considerações finais}

A Alfabetização, sem sombra de dúvidas, é uma das mais importantes etapas da Educação básica. É um processo que começa antes da entrada do aluno na escola, e certamente se estende ao longo de sua vida. Aprendemos cotidianamente novas linguagens, formas de se expressar, produzir sentido, diferentes formas de leitura. Assim, abrir nossos horizontes quanto as práticas e concepções de Alfabetização é primordial. É compreender que, para uma educação de qualidade, a Alfabetização precisa estar em constante renovação, conhecendo os contextos de seu alunado, acompanhando as mudanças sociais, culturais e tecnológicas, buscando sempre a melhor forma de incorporá-las.

Neste âmbito, as formações continuadas tornam-se imprescindíveis, sejam elas ao nível macro ou micro. Um docente comprometido com seu fazer está sempre buscando aperfeiçoamento, melhoria de sua condição de trabalho, investindo na sua qualidade profissional (VEIGA, 2010). O PNAIC, como espaço de formação, proporciona oportunidades de reflexão sobre a prática docente, oferece possíveis mudanças, há oportunidade de reflexão, diálogo com demais profissionais, aprofundamento teórico, aprendizagem.

No entanto, devemos nos alertar para o fato de que os problemas na Alfabetização não serão sancionados somente pelo professor. Street (2004) já dizia que não nos basta ter um letramento único e autônomo, que simplesmente precisa ser transportado para os lugares para a salvação dos problemas. Afinal, se a salvação da Alfabetização se baseasse somente nas formações continuadas, os alunos ainda não estariam, em sua maioria, em nívisl tão baixos de leitura e escrita ${ }^{8}$. A iniciativa do PNAIC tem muito a agregar para as práticas docentes, contanto que os professores, reflexivamente, consigam adequar às teorias apreendidas nas práticas reais em que cada um permanece.

As ações realizadas pelo PNAIC vieram ao encontro de necessidades educativas, constituindo tentativa de intervenção necessária para melhoria da educação. No entanto, precisamos olhar para além dos profissionais que atuam

\footnotetext{
8 Na edição de 2016 da ANA, 54,7\% dos alunos brasileiros ficaram no nível 1 e 2 em leitura; $33,95 \%$ ficaram nos níveis 1,2 e 3 em escrita. Neste exame, que tem o $3^{\circ}$ ano do Ensino Fundamental como público, a categoria de leitura vai de 1 a 4 , e a categoria de escrita vai de 1 a 5 .
} 
nas escolas: infraestrutura, condições de trabalho, características e cultura da comunidade escolar, gestão... são aspectos que também interferem no sucesso ou fracasso de uma educação de qualidade.

A questão da Alfabetização foi e sempre será processo que exige reflexão e, sobretudo, pesquisas, destacando sua complexa e importante função social.

\section{Referências}

ALBUQUERQUE, E. B. C. Conceituando alfabetização e letramento. In: ANTOS, C. F.; MENDONÇA, M. (orgs.). Alfabetização e letramento: conceitos e relações. Belo Horizonte: Autêntica, 2007.

ANTUNES, I. Aula de Português: encontro \& interação. São Paulo: Parábola Editorial, 2003.

BAKHTIN, M. Marxismo e filosofia da linguagem. 5.a ed. São Paulo: Hucitec, 1981.

BRASIL. Secretaria de Educação Básica. Diretoria de Apoio à Gestão Educacional. A criança no Ciclo de Alfabetização. Caderno 2. Brasília: DF, 2015b.

BRASIL. Secretaria de Educação Básica. Diretoria de Apoio à Gestão Educacional. A oralidade, a leitura e a escrita no ciclo de alfabetização. Caderno 5. Brasília: DF, 2015c.

BRASIL. Secretaria de Educação Básica. Diretoria de Apoio à Gestão Educacional. Pacto Nacional Pela Alfabetização na Idade Certa: Apresentação. Brasília: DF, 2015a.

BRASIL. Ministério da Educação. Pacto Nacional Pela Alfabetização na Idade Certa. Formação do Professor Alfabetizador: caderno de apresentação. Brasilia: DF, 2012.

BRASIL. Ministério da Educação. Planejando a próxima década: conhecendo as 20 metas do Plano Nacional de Educação. Secretaria de Articulação com os Sistemas de Ensino (MEC/SASE), 2014. Disponível em: <http://pne.mec.gov.br/pdf/pne_conhecendo_20_metas.pdf>. Acesso em: 05 de maio de 2018.

BRASIL. Ministério da Educação. Secretaria de Educação Básica. Documento Orientador. Brasília: DF, 2017a.

BRASIL. Ministério da Educação. Secretaria de Educação Básica. Pró Letramento: Programa de formação continuada de professores dos anos/séries iniciais do Ensino Fundamental: alfabetização e linguagem. Brasília: DF, 2007.

BRASIL. Ministério da Educação. Secretaria de Educação Fundamental. Programa de Formação de Professores Alfabetizadores. Brasília: DF, 2001. 
Disponivel em: http://portal.mec.gov.br/seb/arquivos/pdf/Profa/guia_for_1.pdf Acesso em: 03 de maio de 2018.

BRASIL. Ministério da Educação. Secretaria de Educação Fundamental. Referenciais para Formação dos Professores. Brasília: DF, 1999. Disponível em:<http://www.dominiopublico.gov.br/download/texto/me002179.pdf >Acesso em: 03 de maio de 2018.

BRASIL. Ministério da Educação. Portaria n 826. Brasília: DF, 2017b.

LIBÂNEO, J. C. Organização e gestão da escola: teoria e prática. Goiânia: Editora Alternativa, 2004.

SILVEIRA, E. et al. Alfabetização na perspectiva do Letramento: letras e números nas práticas sociais. Florianópolis: UFSC/CED/NUP, 2016.

SOARES, M. Alfabetização e Letramento: caminhos e descaminhos. São Paulo: Pátio, 2004.

SOARES, M. Letramento: um tema em três gêneros. 4. ed. Belo Horizonte: Autêntica, 2010.

SOUZA, C. Políticas Públicas: questões temáticas e de pesquisa. Caderno CRH, n. 39, jul./dez. Salvador, 2003.

STREET, B. V. Letramentos sociais: abordagens críticas do letramento no desenvolvimento, na etnografia e na educação. Tradução de Marcos Bagno. 1 ed. São Paulo: Parábola Editorial, 2014.

VEIGA, I. P. A. Alternativas pedagógicas para formação do professor da educação superior. In: VEIGA, I. P. A.; VIANA, C. M. Q. Q (orgs.). Docentes para a educação superior: processos formativos. Campinas: Papirus, 2010. p. 13-28.

ZEICHNER, K. M. Educating reflective teachers for learner cenetred-education possibilities and contradictions. In: GIMENEZ, T. (Org.). Ensinando e aprendendo Inglês na Universidade: formação de professores em tempos de mudança. Londrina: ABRAPUI, 2003.

\section{Sobre os autores}

\section{Lainy Martinelli dos Santos}

lainy-sgp@hotmail.com

Mestra pelo Programa de Pós-Graduação em Ensino na Educação Básica (UFES). Licenciada em Pedagogia pela UFES, com ênfase em Alfabetização e Linguagens.

\section{Zaira Bomfante dos Santos}

zbomfante@gmail.com

Doutora em Estudos Linguísticos pela UFMG. Docente da Universidade Federal do Espírito Santo, Departamento de Educação e Ciências Humanas e Docente Permanente do Programa de Pós-graduação em Ensino na Educação Básica PPGEEB CEUNES, UFES, São Mateus, ES. 